\title{
Raman spectroscopy and imaging of Bernal-stacked bilayer graphene synthesized on copper foil by chemical vapor deposition: Growth dependence on temperature
}

\author{
M. Fabiane ${ }^{1,2}$, M.J. Madito ${ }^{1}$, A. Bello ${ }^{1}$, and N. Manyala ${ }^{1 *}$ \\ ${ }^{1}$ Department of Physics, Institute of Applied Materials, SARChI Chair in Carbon Technology \\ and Materials, University of Pretoria, Pretoria 0028, South Africa
}

${ }^{2}$ National University of Lesotho, Department of Physics and Electronics, P.O. Roma, Lesotho

\begin{abstract}
We report on the effect of temperature on the growth of bilayer graphene on a copper foil under atmospheric pressure chemical vapor deposition (AP-CVD). Before characterization of the AP-CVD bilayer graphene, a high-quality graphene flake was obtained from the Kish bulk graphite by micro-mechanical exfoliation and characterized using Raman spectroscopy and imaging. The Raman data of the exfoliated, high-quality graphene flake shows monolayer and bilayer graphene and was compared to the Raman data of AP-CVD graphene. Raman spectroscopy of AP-CVD graphene shows bilayer films that exhibit predominantly Bernal stacking with an $\mathrm{I}_{2 \mathrm{D}} / \mathrm{I}_{\mathrm{G}}$ ratio of $\sim 1$. At low growth temperature $\left(\sim 780{ }^{\circ} \mathrm{C}\right)$, Raman disorder-related peak intensity in the AP-CVD graphene is high and decreases with an increase in growth temperature to the lowest disorder intensity at $\sim 973{ }^{\circ} \mathrm{C}$. The selected area electron diffraction (SAED) and atomic force microscopy (AFM) average step height analysis showed the thickness of the bilayer graphene. The AP-CVD graphene is uniform at low growth temperatures $\left(\sim 780^{\circ} \mathrm{C}\right)$ with a high disorder and becomes non-uniform at high growth temperatures $\left(\sim 867-973{ }^{\circ} \mathrm{C}\right)$ with a very low disorder as bilayer graphene evolve to form islands with an average lateral size of $<10 \mu \mathrm{m}$. Competition between carbon adatoms supply through dehydrogenation of the $\mathrm{CH}_{x}$ species, mobility and desorption rate of the carbon-adatom species for nucleation of the bilayer graphene as a function of temperature is elucidated. This study provides further insight into the growth mechanisms of bilayer graphene by AP-CVD on $\mathrm{Cu}$.
\end{abstract}

Keywords: Graphene, AP-CVD, Copper foil, Bernal-stacked bilayer, exfoliated graphene

\section{Introduction}

Research has proved graphene synthesis by various methods such as the mechanical exfoliation of natural (Kish) graphite flakes and the transition metal-assisted chemical vapor deposition (CVD) that has shown unequivocal capacity to produce large-area graphene that has a potential use in transparent conducting electrodes, ${ }^{[1-4]}$ supercapacitors ${ }^{[5-8]}$ and integration with current complementary metal oxide semiconductor (CMOS) technology. ${ }^{[9-11]}$ Although much time and effort have been applied to improve CVD graphene, most of the

\footnotetext{
${ }^{*}$ Corresponding Author: Tel: +27 (0)12 4203549 and E-mail address:

ncholu.manyala@up.ac.za (N. Manyala)
} 
advances have been achieved primarily through empirical optimization of the growth parameters. ${ }^{[12]}$ In CVD synthesis of graphene, $\mathrm{Cu}$ is a favourable catalyst due to its very low solubility of carbon (i.e. $<0.001$ at $\%$ at $1000{ }^{\circ} \mathrm{C}$ ) ${ }^{[13]}$ low cost and high etchability, and $\mathrm{Cu}$ typically grows a substrate size uniform monolayer graphene. However, CVD synthesis of uniform, defect-free (high-quality) large-area bilayer and multilayer graphene on $\mathrm{Cu}$ substrate has proved to be more difficult. For instance, a CVD Bernal (AB)-stacked bilayer graphene synthesized on $\mathrm{Cu}$ only forms polycrystalline film consisting of discrete domains with a few micrometer size though the interest is in achieving a large-area AB-stacked bilayer graphene. ${ }^{[14-18]}$ The interest in AB-stacked bilayer graphene is motivated by its tunable bandgap of up to $250 \mathrm{mV}$ when an external electric field is applied perpendicular to the two superimposed layers for practical applications such as graphene-based field-effect transistors (FETs). ${ }^{[19]}$ The challenge of CVD synthesis of uniform, high-quality large-area bilayer and multilayer graphene on $\mathrm{Cu}$ substrate is ascribed primarily to the low decomposition rate of hydrocarbons on the $\mathrm{Cu}$ surface (partial dehydrogenation of the $\mathrm{CH}_{x}$ species $\left.(x=1,2,3)\right)$. ${ }^{[14-}$ ${ }^{16,20-22]}$ In previous studies, atmospheric-pressure CVD (AP-CVD) was used to demonstrate a low hydrocarbon decomposition rate of $\mathrm{Cu}$ surface which was enhanced by alloying $\mathrm{Cu}$ with $\mathrm{Ni}$ to achieve a large-area (or substrate size) AB-stacked bilayer graphene. ${ }^{[23,24]}$ However, the AP-CVD temperature dependence of AB-stacked bilayer graphene growth on $\mathrm{Cu}$ substrate was not investigated and this study aims at such investigation. AP-CVD is a facile synthesis approach and allows high growth temperatures (below substrates melting points) without sublimation of substrates.

Furthermore, various methods are used to characterize the CVD graphene and amongst these methods, Raman spectroscopy and imaging is a versatile, well-known reliable and technique to study properties of graphene, for instance, to determine the number of graphene layers and the stacking order in few layers of graphene samples. ${ }^{[23,25-30]}$ In this study, AP-CVD temperature dependence of $\mathrm{AB}$-stacked bilayer graphene growth on $\mathrm{Cu}$ substrate was investigated. Raman spectroscopy and imaging were used to characterize the synthesized APCVD bilayer graphene. In the characterization of bilayer graphene, a high-quality graphene flake obtained from the Kish bulk graphite by micro-mechanical exfoliation using scotch tape was characterized using Raman spectroscopy and imaging and the results consisted of monolayer and bilayer graphene as interpreted. The Raman data of the exfoliated graphene flake was compared to the Raman data of AP-CVD graphene. The Raman imaging/mapping, AFM average step height analysis and the SAED data showed that the as-grown graphene film is predominantly bilayer. Under the experimental conditions used in this study, the bilayer graphene does not fully evolve to cover the substrate at higher temperatures.

\section{Experimental}

For the AP-CVD temperature dependence of bilayer graphene growth, the temperature of the growth chamber was calibrated before graphene growth using an adjustable thermocouple (chromel-alumel thermocouple, type K) inserted into the chamber so that the temperature could be measured at each centimetre from the highest temperature zone corresponding to the center of the furnace (see Fig. 1(a)). The thermocouple of the furnace registered $918{ }^{\circ} \mathrm{C}$ at the tube centre, while the adjustable thermocouple read $973{ }^{\circ} \mathrm{C}$ at the highest temperature zone (center of the tube furnace). In this study, the temperature reported is that of the adjustable thermocouple. During graphene synthesis, the temperature was first ramped up from room temperature to $1050{ }^{\circ} \mathrm{C}$ (measured at the highest temperature zone (center) of the furnace) and was maintained at this temperature for 10 minutes in an $\mathrm{Ar}$ and $\mathrm{H}_{2}$ atmosphere (see 

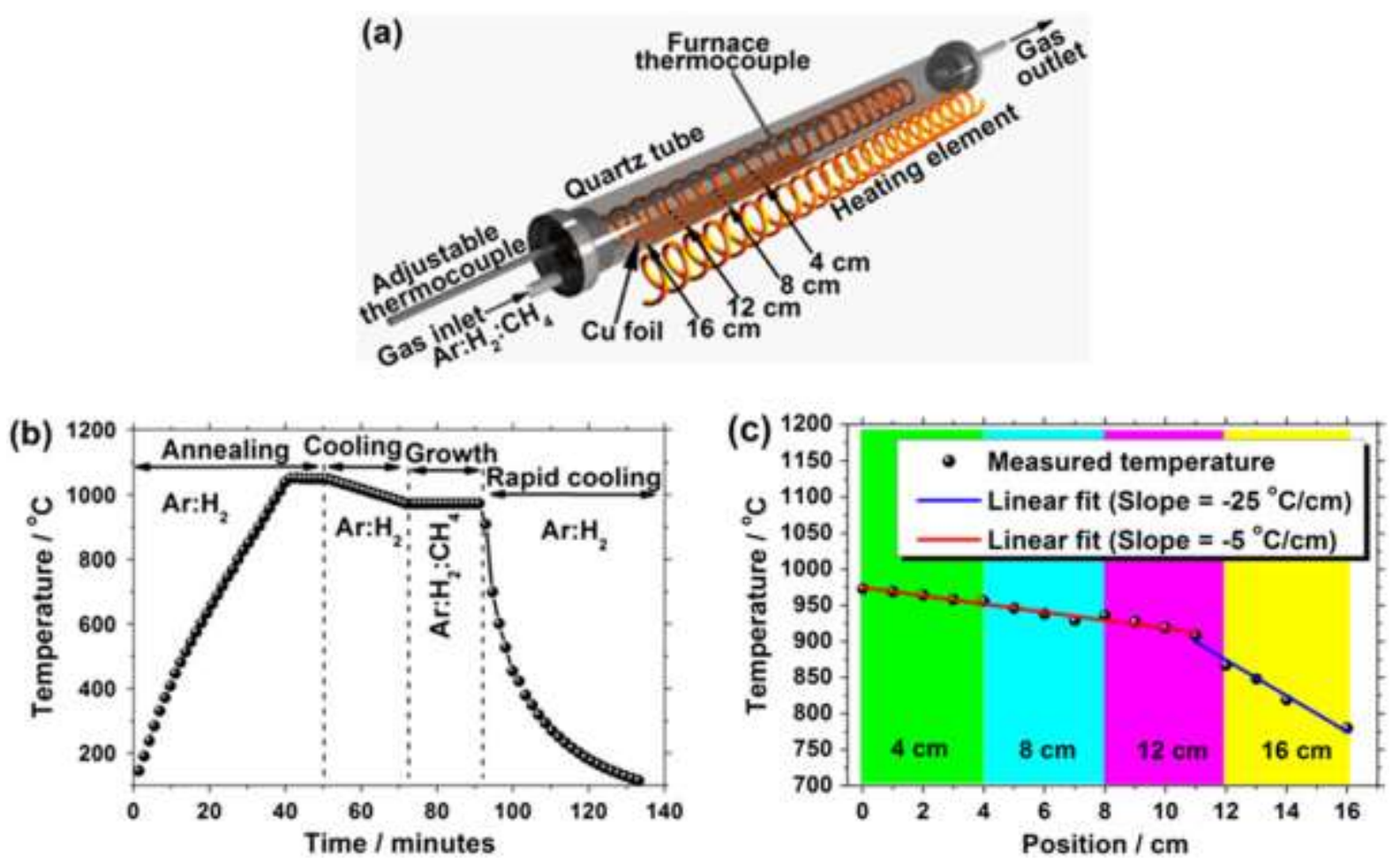

Figure 1. (a) Schematic diagram of the furnace tube showing a $16 \mathrm{~cm}$ long copper foil divided into four segments placed during graphene growth. (b) A temperature profile of AP-CVD system measured at the center of a quartz tube using adjustable thermocouple for the growth of graphene. (c) Temperature measurements taken at each centimetre from the center of a quartz tube $\left(973^{\circ} \mathrm{C}\right)$ by the adjustable thermocouple.

Fig. 1(b)). Thereafter, it was lowered to $973{ }^{\circ} \mathrm{C}$ and a succession of temperature measurements was taken at each centimetre from the highest temperature zone by the adjustable thermocouple as shown in Fig. 1 (c). The thermocouple was moved from the highest temperature zone towards the low-temperature zone in steps of $1 \mathrm{~cm}$ and the temperature was allowed to stabilize for 3 minutes at each new position before recorded. The $16 \mathrm{~cm}$ long $\mathrm{Cu}$ foil ( $25 \mu \mathrm{m}$ thick foils, $99.8 \%$, Alfa Aesar) was loaded into the quartz tube and placed along the length of one-half of the furnace's heating elements so that it spanned the length of the element $\sim 16 \mathrm{~cm}$ (see schematic in Fig. 1(a)). In this way, the gas flow rate through the quartz tube was kept constant while the temperature varied along the length of the $\mathrm{Cu}$ foil. In Fig. 1 (c), it can be seen that temperature variation in $4 \mathrm{~cm}\left(\sim 956-973{ }^{\circ} \mathrm{C}\right)$ and $8 \mathrm{~cm}\left(\sim 939-956{ }^{\circ} \mathrm{C}\right)$ pieces of $\mathrm{Cu}$ foil is very small $\left( \pm 5^{\circ} \mathrm{C} / \mathrm{cm}\right)$ compare to $12 \mathrm{~cm}$ $\left(\sim 867-936^{\circ} \mathrm{C}\right)$ and $16 \mathrm{~cm}\left(\sim 780-862^{\circ} \mathrm{C}\right)$ pieces which have large temperature variation of $\pm 25^{\circ} \mathrm{C} / \mathrm{cm}$. Consequently, AP-CVD growth dependency on temperature was evaluated over a high-temperature zone $\left(\sim 939-973{ }^{\circ} \mathrm{C}\right)$ with small temperature variation and a lowtemperature zone $\left(\sim 780-862{ }^{\circ} \mathrm{C}\right)$ with a large temperature variation. Graphene was synthesized by AP-CVD in a quartz tube furnace from a mixture of Ar: $\mathrm{CH}_{4}: \mathrm{H}_{2}=300: 10: 9$ sccm gases on a $\mathrm{Cu}$ foil. The synthesis process and the growth temperature (measured at the highest temperature zone) are shown schematically and graphically in Fig. 1(a) and (b) respectively. After the graphene growth, the sample was rapidly cooled by pushing the quartz tube to the cooler part of the furnace and then was let to cool naturally to room temperature before it could be taken out of the tube. ${ }^{[31]}$ The graphene was transferred onto $300 \mathrm{~nm}$ thick $\mathrm{SiO}_{2} / \mathrm{Si}$ substrates and TEM grids by spin coating a thin layer of polymethyl methacrylate (PMMA) on the as-grown graphene on $\mathrm{Cu}$ foil. For characterization of bilayer graphene 
obtained using AP-CVD, high-quality graphene flakes were first obtained from the Kish bulk graphite by micro-mechanical exfoliation using scotch tape and characterized for comparison with the AP-CVD graphene. The Raman data obtained from the exfoliated graphene flake is presented in the supporting information.

A T64000 micro-Raman spectrometer (HORIBA Scientific, Jobin Yvon Technology) with a $514 \mathrm{~nm}$ laser wavelength, $50 \times$ objective and spectral acquisition time of $120 \mathrm{~s}$ was used to characterize the as-grown samples on the $\mathrm{Cu}$ foil and those transferred onto $\mathrm{SiO}_{2} / \mathrm{Si}$ substrates. Raman imaging of the samples was carried out using a WITec alpha 300R+ confocal Raman system (WITec $\mathrm{GmbH})$ at $532 \mathrm{~nm}$ laser wavelength $(2.33 \mathrm{eV})$ through a numerical aperture of 0.9 with a diffraction-limited spot size of $360 \mathrm{~nm}$ on the sample surface and $100 \times$ magnifications, which allows an image spatial resolution of about $360 \mathrm{~nm}$. A spectral resolution was $3 \mathrm{~cm}^{-1}$ and the Raman system laser power was set as low as $1.6 \mathrm{~mW}$ in order to minimize heating effects. Electron diffraction pattern of graphene was obtained with High-resolution transmission electron microscopy (HRTEM) (Jeol JEM-2100F Field Emission Electron Microscope, with a maximum analytical resolution of $200 \mathrm{kV}$ and a probe size under $0.5 \mathrm{~nm}$ ). The topographical image of graphene sample transferred onto the $\mathrm{SiO}_{2} / \mathrm{Si}$ substrate was obtained using a Dimension Icon atomic force microscope (AFM) (Bruker AXS) with NanoScope Analysis software in Scan Asyst mode. The AFM cantilever with a spring constant of $2.8 \mathrm{~N} / \mathrm{m}$ and a nominal resonance frequency of $75 \mathrm{kHz}$ were used.

\section{Results and discussions}

In the AP-CVD graphene, the Raman spectra of the as-grown graphene were obtained directly from the $16 \mathrm{~cm}$ long $\mathrm{Cu}$ foil at intervals of $1 \mathrm{~cm}$ from the low-temperature region $\left(\sim 780{ }^{\circ} \mathrm{C}\right)$ to the high-temperature region $\left(\sim 973{ }^{\circ} \mathrm{C}\right)$ at the center of the furnace as shown in Fig. 2. Figure 2 shows the typical Raman spectra of as-grown graphene on $\mathrm{Cu}$ foil after subtraction of $\mathrm{Cu}$ luminescent background by performing a background subtraction during the data analysis and care was taken to ensure that the regions of the spectrum containing Raman peaks are not altered. For short acquisition time of good Raman spectra and imaging, as-grown graphene on $\mathrm{Cu}$ foil was transferred onto the $\mathrm{SiO}_{2} / \mathrm{Si}$ substrate. The $16 \mathrm{~cm}$ long graphene/Cu foil was cut into four samples each $4 \mathrm{~cm}$ long and transferred onto $\mathrm{SiO}_{2} / \mathrm{Si}$ substrates separately. Figure 3(a) - (d) show the optical micrographs of each $4 \mathrm{~cm}$ long graphene samples transferred to $\mathrm{SiO}_{2} / \mathrm{Si}$ substrates corresponding to temperature ranges of $\sim 780-862{ }^{\circ} \mathrm{C}, \sim 867-936{ }^{\circ} \mathrm{C}, \sim 939-956{ }^{\circ} \mathrm{C}$ and $\sim 956-973{ }^{\circ} \mathrm{C}$. In the low-temperature range $\left(\sim 780-862{ }^{\circ} \mathrm{C}, 16 \mathrm{~cm}\right.$ piece), the optical micrograph suggest a continuous graphene with a uniform thickness and at higher temperatures $\left(\sim 867-973{ }^{\circ} \mathrm{C}, 12 \mathrm{~cm}\right.$ to $4 \mathrm{~cm}$ pieces) the graphene thickness varies as presented by each micrograph color contrast since the optical micrograph displays the image color contrast between monolayer and a few layer graphene. It was observed for exfoliated graphene flake that Raman imaging of the $G$ mode displays the image color contrast between monolayer and bilayer graphene (see Fig. S1(c) (Supporting Information)). Therefore, to confirm the thickness variation in the graphene samples, the Raman imaging of the $\mathrm{G}$ mode of each sample was obtained as shown in Fig. 4. 


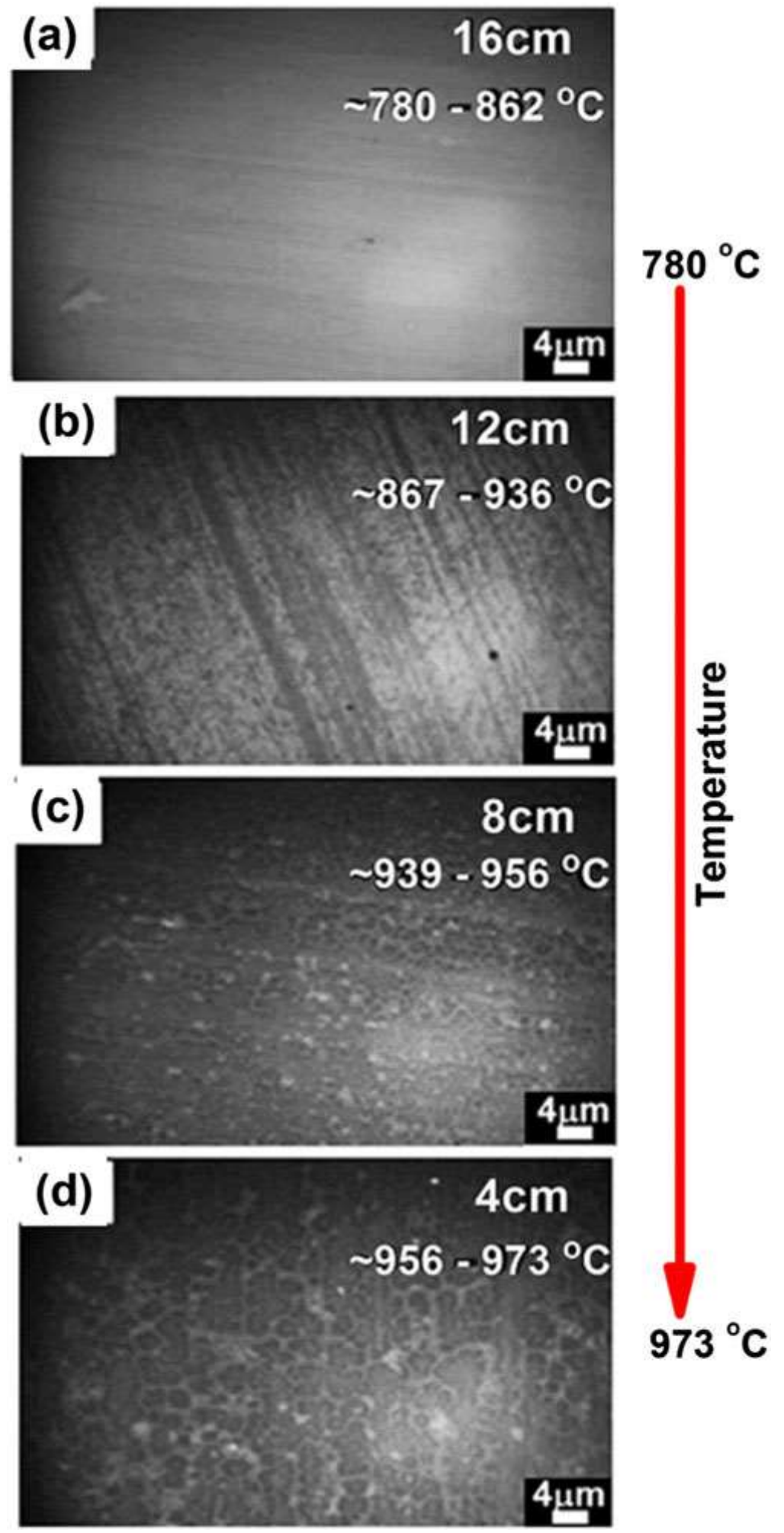

Figure 3. The optical micrographs of graphene samples transferred onto $\mathrm{SiO}_{2} / \mathrm{Si}$ substrates corresponding to temperature ranges of (a) $\sim 780-862{ }^{\circ} \mathrm{C}$, (b) $\sim 867-936{ }^{\circ} \mathrm{C}$, (c) $\sim 939-956{ }^{\circ} \mathrm{C}$ and (d) $\sim 956-973{ }^{\circ} \mathrm{C}$ respectively. 

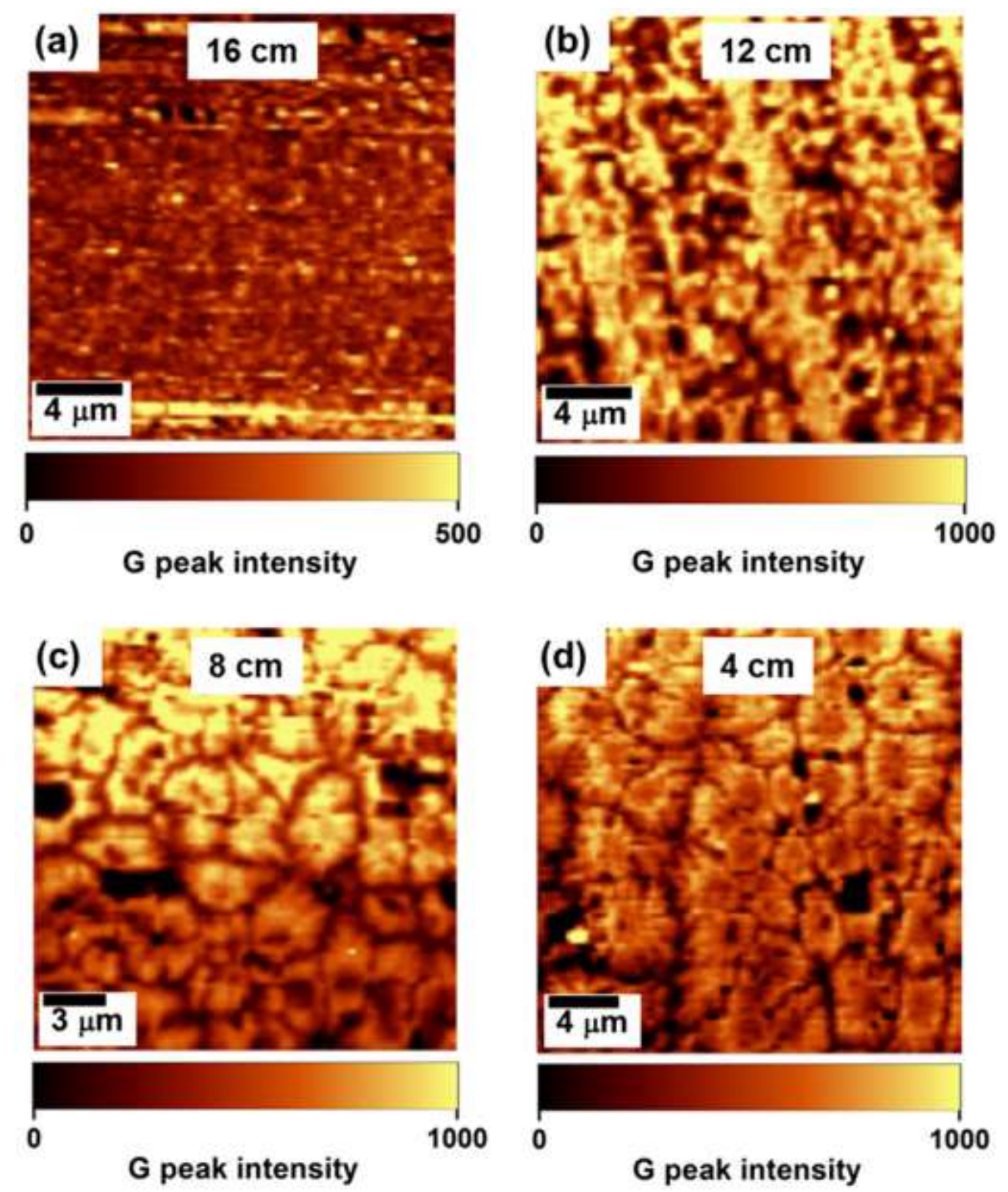

Figure 4. (a)-(d) Raman imaging of the $G$ mode for the graphene samples (i.e. 16, 12, 8 and $4 \mathrm{~cm}$ pieces corresponding to temperature ranges of (a) $\sim 780-862{ }^{\circ} \mathrm{C}$, (b) $\sim 867-936{ }^{\circ} \mathrm{C}$, (c) $\sim 939-956{ }^{\circ} \mathrm{C}$ and (d) $\sim 956-973$ ${ }^{\circ} \mathrm{C}$ respectively) transferred onto $\mathrm{SiO}_{2} / \mathrm{Si}$ substrates.

In Fig. 4, at lower temperatures $\left(\sim 780-862{ }^{\circ} \mathrm{C}, 16 \mathrm{~cm}\right.$ piece (Fig. 4(a)), the $\mathrm{G}$ mode imaging confirms a continuous graphene with a uniform thickness as indicated by optical micrograph. However, as temperature increases $\left(\sim 867-973{ }^{\circ} \mathrm{C}\right.$ ) a dark background (low $\mathrm{G}$ peaks intensities regions) becomes clear as shown in the images of 12 to $4 \mathrm{~cm}$ pieces (Fig. 4(b-d) which confirm non-uniform thickness in graphene obtained within the temperature range of these pieces. From the images, it can be seen that the few layer islands are clearly visible at the highest temperature of $\sim 973{ }^{\circ} \mathrm{C}$ (Fig. 4(d)). Additionally, the $\mathrm{G}$ peaks intensities in the images of 12, 8 and $4 \mathrm{~cm}$ pieces (see the scale bar) is almost twice that of the $16 \mathrm{~cm}$ piece suggesting that 12,8 and $4 \mathrm{~cm}$ pieces are mostly comprised of graphene with a thickness that is almost double that of the $16 \mathrm{~cm}$ piece since the $\mathrm{G}$ peak intensity follows a linear trend as the number of layers increases from mono to multilayer graphene as mentioned in Fig. S1 
(Supporting Information). Furthermore, Fig. 5 shows the mapping of the 2D to G peaks intensities ratio $\left(\mathrm{I}_{2 \mathrm{D}} / \mathrm{I}_{\mathrm{G}}\right)$ which depicts that a $16 \mathrm{~cm}$ piece graphene has $\mathrm{I}_{2 \mathrm{D}} / \mathrm{I}_{\mathrm{G}}$ of $\sim 1$ (blue-togreen color in Fig. 5(a)) and for 12,8 and $4 \mathrm{~cm}$ pieces a graphene is mainly composed of $\mathrm{I}_{2 \mathrm{D}} / \mathrm{I}_{\mathrm{G}}$ of $\sim 1$ and small areas of $\mathrm{I}_{2 \mathrm{D}} / \mathrm{I}_{\mathrm{G}}$ of $\sim 2$ (yellow-to-red color in Fig. $5\left(\mathrm{~b}-\mathrm{d}\right.$ )). The $\mathrm{I}_{2 \mathrm{D}} / \mathrm{I}_{\mathrm{G}}$ of $\sim 1$ observed from the mapping correspond to that observed from the Raman spectra in Fig. 2 and Fig. S1 (Supporting Information) for exfoliated bilayer graphene and this ratio suggest that the as-grown graphene is predominantly AB-stacked bilayer graphene. ${ }^{[32]}$ In Fig. 5(b d), small areas with $\mathrm{I}_{2 \mathrm{D}} / \mathrm{I}_{\mathrm{G}}$ of $\sim 2$ (yellow-to-red color) correspond to darker areas in Fig. 4(bd) which could be monolayer graphene.
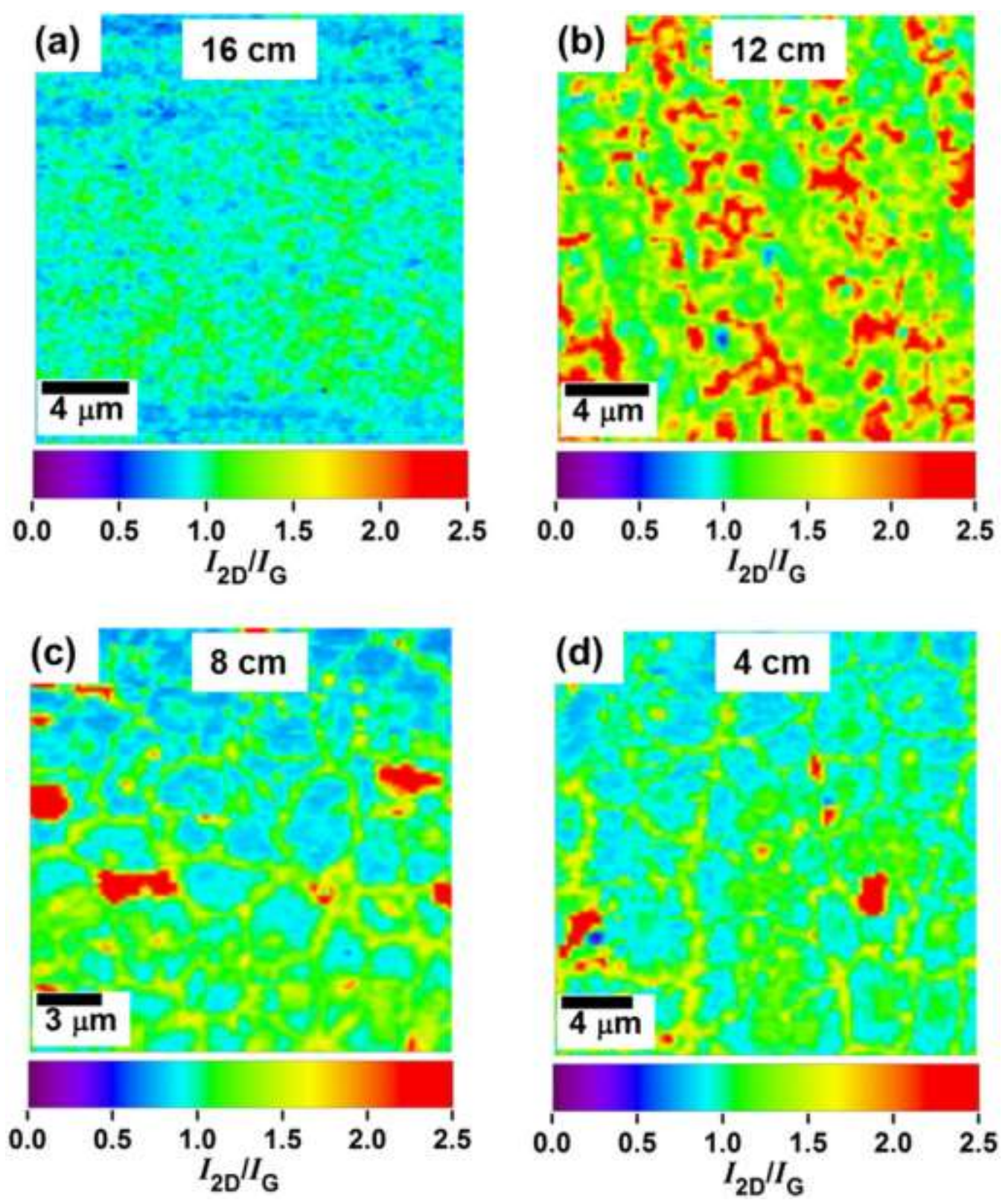

Figure 5. (a)-(d) Raman mapping of the $2 \mathrm{D}$ to $\mathrm{G}$ peaks intensities ratio $\left(\mathrm{I}_{2 \mathrm{D}} / \mathrm{I}_{\mathrm{G}}\right)$ for the graphene samples (i.e. $16,12,8$ and $4 \mathrm{~cm}$ pieces corresponding to temperature ranges of (a) $\sim 780-862{ }^{\circ} \mathrm{C}$, (b) $\sim 867-936{ }^{\circ} \mathrm{C}$, (c) $\sim 939-$ $956{ }^{\circ} \mathrm{C}$ and (d) $\sim 956-973{ }^{\circ} \mathrm{C}$ respectively) transferred onto $\mathrm{SiO}_{2} / \mathrm{Si}$ substrates. 

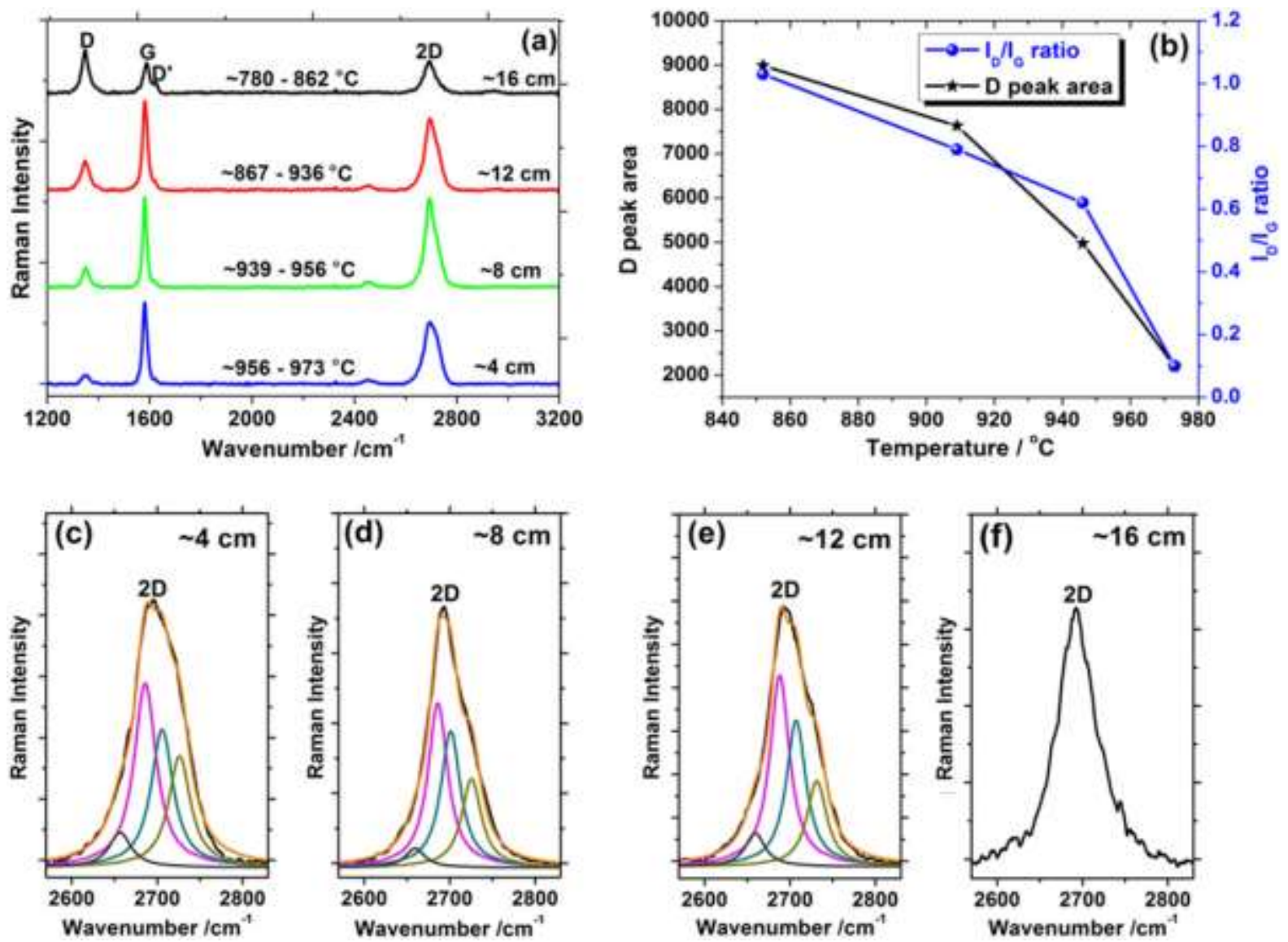

Figure 6. (a) Raman spectra of each of the graphene samples (i.e. 16, 12, 8 and $4 \mathrm{~cm}$ pieces corresponding to temperature ranges of $\sim 780-862{ }^{\circ} \mathrm{C}, \sim 867-936{ }^{\circ} \mathrm{C}, \sim 939-956{ }^{\circ} \mathrm{C}$ and $\sim 956-973{ }^{\circ} \mathrm{C}$ respectively) transferred onto $\mathrm{SiO}_{2} / \mathrm{Si}$ substrates. (b) The area under $\mathrm{D}$ peak and the $\mathrm{D}$ to $\mathrm{G}$ peaks intensities ratio $\left(\mathrm{I}_{\mathrm{D}} / \mathrm{I}_{\mathrm{G}}\right)$ of Raman spectra of each of the graphene samples. (c)-(f) The 2D mode of the Raman spectra in (a) and the corresponding Lorentzian fits.

Similar to exfoliated graphene flake, to determine the number of layers in the AP-CVD samples, the Raman spectra which show the D, G, D' and 2D modes were obtained from each of the four samples in Fig. 4 (see Fig. 6(a)). In the samples, the calculated D to G peaks intensities ratio $\left(\mathrm{I}_{\mathrm{D}} / \mathrm{I}_{\mathrm{G}}\right)$ increases with decreasing growth temperature (see Fig. 6(b)) suggesting low-quality (or high disorder) graphene at low growth temperatures $\left(<900{ }^{\circ} \mathrm{C}\right)$ and high-quality graphene at growth temperatures higher than $900{ }^{\circ} \mathrm{C}$. The area under the $\mathrm{D}$ peak increases with decreasing growth temperature (Fig. 6(b)) suggesting an increase in the contribution of defects in graphene with a decrease in growth temperature which could be attributed to the partial dehydrogenation of the $\mathrm{CH}_{x}$ species $(x=1,2,3)$ due to low growth temperature and high background pressure of AP-CVD. Contrary to low-pressure CVD which has a lower density of impurities and residual gas due to high vacuum, ${ }^{[21]}$ AP-CVD grows high disorder graphene on $\mathrm{Cu}$ substrate at lower growth temperatures $\left(<900{ }^{\circ} \mathrm{C}\right)$. However, at higher growth temperatures $\left(\sim 1000^{\circ} \mathrm{C}\right)$, AP-CVD grows high-quality graphene. To determine the number of layers in the samples the Lorentzian fits of the $2 \mathrm{D}$ mode were obtained (Fig. 6(c) - (e)) similar to that of exfoliated graphene flake (Fig. S1(e) (Supporting Information)). The Lorentzian fits for graphene achieved at lower growth temperatures $\left(\sim 780-862{ }^{\circ} \mathrm{C}, 16 \mathrm{~cm}\right.$ piece) were not obtained due to high disorder (high D peak intensity relative to $G$ peak) which could influence the broadening of the $2 \mathrm{D}$ peak. However, it is worth mentioning that $2 \mathrm{D}$ mode originates from the double resonance process that involves 
two in-plane transverse optical modes (iTO) phonons and is independent of defects, however, the D mode involves one iTO phonon and one defect. ${ }^{[33]}$ In addition, the Lorentzian fit approach used to distinguish between the numbers of layers in graphene is adopted for highquality graphene (i.e. low D peak intensity relative to $G$ peak). ${ }^{[25,28]}$ Similar to exfoliated graphene flake, the Lorentzian fits as well as the $\mathrm{I}_{2 \mathrm{D}} / \mathrm{I}_{\mathrm{G}}$ ratio of $\sim 1$ demonstrate characteristics of the AB-stacked bilayer graphene. ${ }^{[27,34]}$
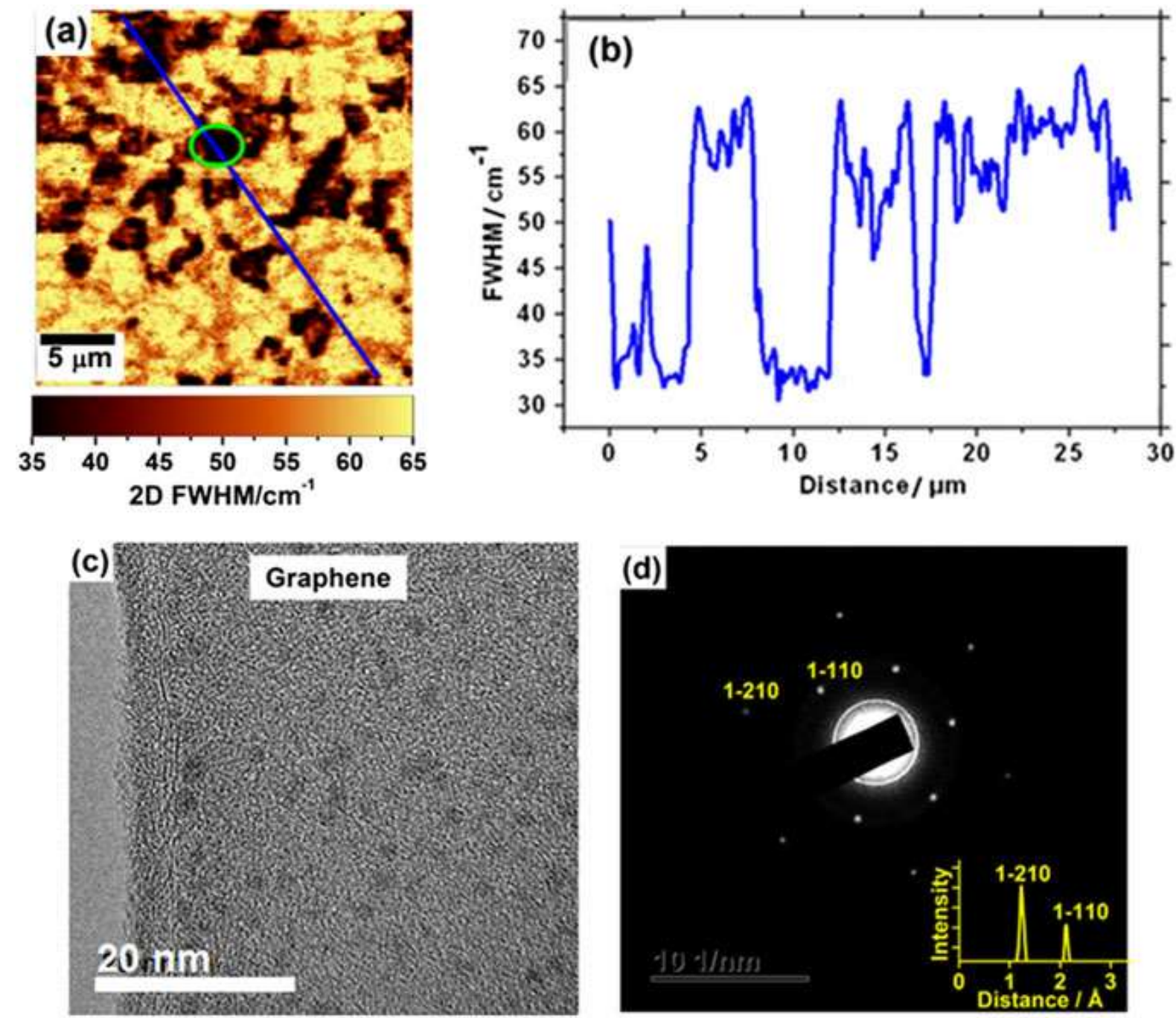

Figure 7. (a) Raman imaging of the $2 \mathrm{D}$ peak FWHM and (b) the corresponding FWHM line profile across the image in (a) for graphene of a $4 \mathrm{~cm}$ piece at $\sim 956-973{ }^{\circ} \mathrm{C}$. (c) A high magnification TEM image for graphene of a $4 \mathrm{~cm}$ piece at $\sim 956-973{ }^{\circ} \mathrm{C}$ and (d) the corresponding selected area electron diffraction (SAED) pattern which shows the diffraction rings intensity profile (inset to the figure).

Raman imaging of the 2D peak full width at half maximum (FWHM) and the corresponding FWHM line profile across the 2D peak FWHM image for the graphene samples show an average value of $55.3 \mathrm{~cm}^{-1}$ (Fig. 7(a) and (b) for $4 \mathrm{~cm}$ piece graphene at $\sim 956-973{ }^{\circ} \mathrm{C}$ ) which compare well with the average values $51 \mathrm{~cm}^{-1},{ }^{[35]} 53 \mathrm{~cm}^{-1[22]}$ and $60.1 \mathrm{~cm}^{-1[18]}$ found in literature for AB-stacked bilayer graphene. The minimum average FWHM $\left(32 \mathrm{~cm}^{-1}\right)$ in Fig. 7(b) corresponding to the dark areas (green circle) in Fig. 7(a) compare well with that of exfoliated graphene flake for monolayer graphene. 
Figure 7(c) and (d) show a high magnification TEM image and selected area electron diffraction (SAED) pattern respectively for graphene of a $4 \mathrm{~cm}$ piece at $\sim 956-973{ }^{\circ} \mathrm{C}$ transferred on a TEM grid. A SAED pattern shows two sets of hexagonal diffraction spots and the corresponding intensity profile (inset to Fig. 7(d)) taken along the inner and outer diffraction rings which were indexed using the Miller - Bravais indices $(h k l)$ for graphite where peaks at $d=1.23 \AA$ and $d=2.13 \AA$ correspond to indices (1-210) for outer hexagon and (1-110) for inner hexagon respectively. ${ }^{[36]}$ An intensity profile (inset to Fig. 7(d)) shows that the intensity of the diffraction spots in the outer hexagon is twice the intensity of the diffraction spots in the inner hexagon, indicating that the set of diffraction spots correspond to an AB-stacked bilayer graphene. Figure 8(a) shows an AFM optical microscope image (showing AFM cantilever and graphene film) for graphene of a $4 \mathrm{~cm}$ piece at $\sim 956-973{ }^{\circ} \mathrm{C}$ transferred onto $\mathrm{SiO}_{2} / \mathrm{Si}$ substrate. In Fig. 8(b), the AFM image of graphene film shows the edge and wrinkles of the graphene sheet shown in Fig. 8(a). From the edge of the graphene film (i.e. from $\mathrm{Si} / \mathrm{SiO}_{2}$ to graphene film along the solid-line in Fig.8 (b)), the height profile was measured as shown in Fig. 8(c) which depicts that the thickness of the graphene film has average value of about $1.5 \mathrm{~nm}$ suggesting bilayer graphene.
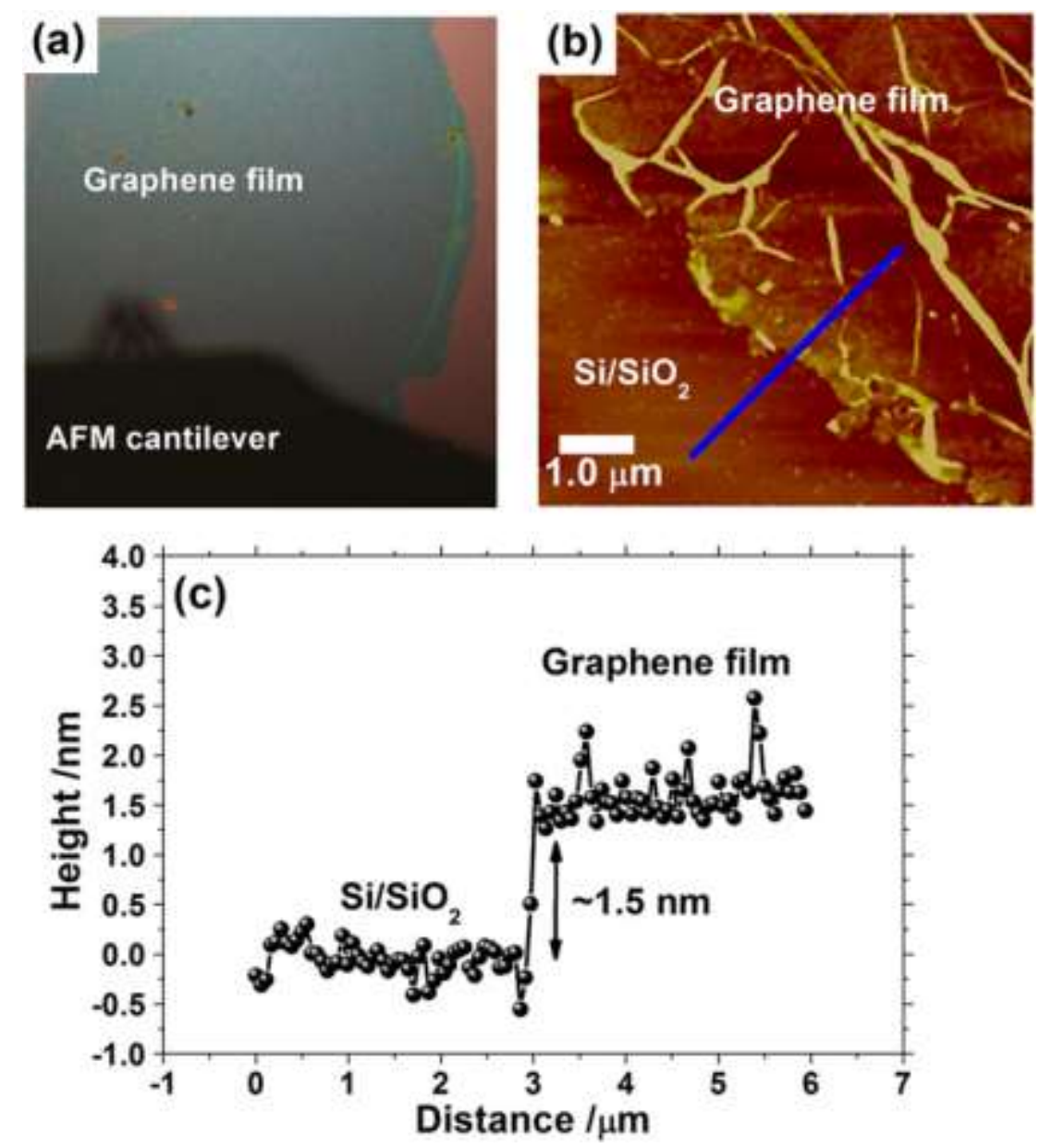

Figure 8. (a) AFM optical microscope image (showing AFM cantilever and graphene film). (b) AFM image of graphene film showing the edge and wrinkles of the sheet. (c) Height profile measured along the solid line in (b). 
In summary, the optical micrographs and the Raman imaging/mapping for graphene samples obtained from 12,8 and $4 \mathrm{~cm}$ pieces corresponding to temperature ranges of $\sim 867-936{ }^{\circ} \mathrm{C}$, $\sim 939-956{ }^{\circ} \mathrm{C}$ and $\sim 956-973{ }^{\circ} \mathrm{C}$ respectively (see Figs. 3, 4 and 5) display growth of graphene which is predominantly AB-stacked bilayer. The SAED and AFM step height analysis confirmed the thickness of the bilayer graphene. The observed islands of bilayer graphene (dark areas in optical micrographs) are part of a continuous monolayer graphene (light areas in optical micrographs). Therefore, since the growth of bilayer graphene is evident from growth temperatures in the range of $\sim 867-973{ }^{\circ} \mathrm{C}$ (12 to $4 \mathrm{~cm}$ pieces) and the light areas (monolayer graphene) in optical micrographs of 12 to $4 \mathrm{~cm}$ pieces compare well with $16 \mathrm{~cm}$ piece optical micrograph, it can be mentioned that a continuous graphene with a uniform thickness observed from the optical micrographs and the Raman imaging/mapping at growth temperatures in the range of $\sim 780-862{ }^{\circ} \mathrm{C}(16 \mathrm{~cm}$ piece $)$ is predominantly high disorder monolayer graphene. The high disorder of this graphene could be attributed to the partial dehydrogenation of the $\mathrm{CH}_{x}$ species $(x=1,2,3)$ at low AP-CVD growth temperatures presumably because $\mathrm{Cu}$ is known to have low decomposition rate of methane gas. ${ }^{[20,21,37]}$ In addition, the high disorder (high D peak intensity) of this graphene could increase the intensity of the G peak through $\mathrm{D}^{\prime}$ peak (G peak right-shoulder shown in Fig. 6(a)) which supposed to be less relative to $2 \mathrm{D}$ peak for monolayer compared to bilayer graphene as demonstrated by Raman imaging of $\mathrm{G}$ mode for exfoliated graphene flake. The high disorder could also contribute to the broadening of the 2D peak resulting in FWHM range (48 $71 \mathrm{~cm}^{-1}$ ) similar to that of high-quality (low D peak intensity) bilayer graphene (see Fig. S2 (Supporting Information)).

To explain the dendritic behaviour of graphene domains observed under the AP-CVD growth for graphene of a $4 \mathrm{~cm}$ piece at $\sim 956-973{ }^{\circ} \mathrm{C}$, the mechanism proposed by Li et al ${ }^{[8]}$ was adopted. The mechanism suggests that the limited space in the interface between the top graphene layer and the $\mathrm{Cu}$ substrate forms a "nano- CVD" chamber. The extreme physical confinements in the nano-CVD chamber result in a lower partial pressure of $\mathrm{CH}_{x}$ species, which manifests in a decreased growth rate. The non-uniformity of precursor distribution in the deposition chamber under AP-CVD is eliminated by the confined space between the top graphene layer and the $\mathrm{Cu}$ catalyst and hence the growth mimics that of low-pressure chemical vapor deposition (LP-CVD) having domains with dendritic appearance resulting from underlayer of a bilayer graphene. ${ }^{[32,39-41]}$

The dependence of graphene domain size on temperature is elucidated by adopting the model and the experimental results of Kim et al. ${ }^{[12,42]}$ In this model, the occurrence of two nucleation regimes is a result of the competition between the processes of adatom capture, surface diffusion and desorption. ${ }^{[12,42]}$ In the low-temperature regime, desorption of carbon adatoms is negligible due to its high activation barrier ${ }^{[12,37]}$ and carbon surface diffusion determines the growth. In the high-temperature regime, desorption is a dominant process and hence the domain growth may be hindered depending on the gas supply. The mechanism was adopted based on the growth of a monolayer graphene whereas it is applied to bilayer graphene growth in this work and our experimental results are in good agreement with it when the so-called underlayer growth mechanism in multilayer graphene is considered. ${ }^{[17,31,43]}$ In the underlayer growth mechanism of multilayers, the subsequent layers grow beneath the top monolayer. ${ }^{[17,31,43]}$ However, such a structure should form at suitably higher temperatures, ${ }^{[38]}$ in this regime, the top layer grows faster and becomes larger than the second layer. This is a desorption-controlled regime. ${ }^{[12]}$ The capture probability of carbon atoms is expected to be higher for the top layer than for the underlayer since the $\mathrm{C}$ atoms first have to pass the edge of the top layer and penetrate under it to the growing underlayer. Carbon atoms are captured on the way and few adatoms may reach the bottom layer, hence 
the top layer grows faster. In the low-temperature regime, desorption is negligible due to the high activation energy barrier and adatom mobility controls the nucleation. ${ }^{[12]}$ In this way, both the top and bottom layers should have a sufficient supply of carbon adatoms to grow and fully cover the substrate. However, in this work, in the low-temperature range of $\sim 780-$ $867{ }^{\circ} \mathrm{C}$ a $\mathrm{Cu}$ catalyst shows a high disorder graphene which could be attributed to the partial dehydrogenation of the $\mathrm{CH}_{x}$ species which would lead to insufficient supply of $\mathrm{C}$ adatoms required for high-quality substrate-size bilayer graphene. In contrast to low-temperature range, in high-temperature range of $\sim 956-973{ }^{\circ} \mathrm{C}$, a high-quality bilayer graphene islands with an average lateral size of $<10 \mu \mathrm{m}$ are evident suggesting that for bilayer graphene growth on $\mathrm{Cu}$ catalyst a CVD growth temperature higher than $900{ }^{\circ} \mathrm{C}$ is essential. Nonetheless, in the model and the experimental results of Kim et al. ${ }^{[12,42]}$, it is clearly demonstrated that for substrate-size graphene to grow on a $\mathrm{Cu}$ catalyst the CVD growth temperature should be approximately $1000{ }^{\circ} \mathrm{C}$.

\section{Conclusions}

We have elucidated the role of temperature in the synthesis of $\mathrm{AB}$-stacked bilayer graphene on $\mathrm{Cu}$ foil. For our growth parameters, the graphene grown at low temperature $(\sim 780-867$ $\left.{ }^{\circ} \mathrm{C}\right)$ is uniform, with a high disorder, while the graphene grown at a higher temperature $(\sim 956$ $-973{ }^{\circ} \mathrm{C}$ ) manifests predominantly as high-quality $\mathrm{AB}$-stacked bilayer graphene islands with an average lateral size of $<10 \mu \mathrm{m}$ and does not fully evolve to cover the substrate except for the top monolayer graphene. This is ascribed to the competition between carbon adatoms supply through dehydrogenation of the $\mathrm{CH}_{x}$ species, mobility and desorption of carbon adatoms during the graphene growth. The dendritic growth similar to the growth under LPCVD is ascribed to the confined space between the top graphene layer and the $\mathrm{Cu}$ catalyst which eliminates the non-uniform distribution of precursors in the AP-CVD graphene growth.

\section{Acknowledgements}

This study is based on research supported by the South African Research Chairs Initiative of the Department of Science and Technology (SARChI-DST) and the National Research Foundation (NRF) (Grant No. 97994). Any opinions, findings and conclusions, or recommendations expressed in this study are those of authors and therefore the NRF and DST do not accept any liability with regard thereto. M.F thanks the University of Pretoria and the NRF for financial support during his PhD studies.

\section{References}

[1] K. S. Kim, Y. Zhao, H. Jang, S. Y. Lee, J. M. Kim, K. S. Kim, J.-H. Ahn, P. Kim, J.Y. Choi, B. H. Hong, Nature 2009, 457, 706.

[2] X. Li, Y. Zhu, W. Cai, M. Borysiak, B. Han, D. Chen, R. D. Piner, L. Colombo, R. S. Ruoff, Nano Lett. 2009, 9, 4359.

[3] S. Bae, H. Kim, Y. Lee, X. Xu, J.-S. Park, Y. Zheng, J. Balakrishnan, T. Lei, H. Ri Kim, Y. Il Song, Y.-J. Kim, K. S. Kim, B. Özyilmaz, J.-H. Ahn, B. H. Hong, S. Iijima, Nat. Nanotechnol. 2010, 5, 574. 
[4] D. Dodoo-arhin, M. Fabiane, A. Bello, N. Manyala, Ind. Eng. Chem. Res. 2013, 52, 14160.

[5] J. Xia, F. Chen, J. Li, N. Tao, Nat. Nanotechnol. 2009, 4, 505.

[6] Z.-S. Wu, K. Parvez, X. Feng, K. Mullen, Nat. Commun. 2013, 4, 2487.

[7] A. Bello, M. Fabiane, D. Dodoo-Arhin, K. I. Ozoemena, N. Manyala, J. Phys. Chem. Solids 2014, 75, 109.

[8] A. Bello, O. O. Fashedemi, J. N. Lekitima, M. Fabiane, D. Dodoo-arhin, Y. Gogotsi, A. T. C. Johnson, N. Manyala, AIP Adv. 2013, 3, 82118.

[9] K. S. Novoselov, A. K. Geim, S. V Morozov, D. Jiang, Y. Zhang, S. V Dubonos, I. V Grigorieva, A. A. Firsov, Science 2004, 306, 666.

[10] Yu-Ming Lin, Hsin-Ying Chiu, K. A. Jenkins, D. B. Farmer, P. Avouris, A. ValdesGarcia, Electron Device Lett. IEEE 2010, 31, 68.

[11] F. Xia, D. B. Farmer, Y.-M. Lin, P. Avouris, Nano Lett. 2010, 10, 715.

[12] H. Kim, C. Mattevi, M. R. Calvo, J. C. Oberg, L. Artiglia, S. Agnoli, C. F. Hirjibehedin, M. Chhowalla, E. Saiz, ACS Nano 2012, 6, 3614.

[13] G. A. López, E. J. Mittemeijer, Scr. Mater. 2004, 51, 1.

[14] A. Guermoune, T. Chari, F. Popescu, S. S. Sabri, J. Guillemette, H. S. Skulason, T. Szkopek, M. Siaj, Carbon 2011, 49, 4204.

[15] W. Liu, H. Li, C. Xu, Y. Khatami, K. Banerjee, Carbon 2011, 49, 4122.

[16] A. Mohsin, L. Liu, P. Liu, W. Deng, I. N. Ivanov, G. Li, O. E. Dyck, G. Duscher, J. R. Dunlap, K. Xiao, G. Gu, ACS Nano 2013, 7, 8924.

[17] S. Nie, W. Wu, S. Xing, Q. Yu, J. Bao, S. Pei, K. F. McCarty, New J. Phys. 2012, 14, 93028.

[18] W. Fang, A. L. Hsu, R. Caudillo, Y. Song, A. G. Birdwell, E. Zakar, M. Kalbac, M. Dubey, T. Palacios, M. S. Dresselhaus, P. T. Araujo, J. Kong, Nano Lett. 2013, 13, 1541.

[19] Y. Zhang, T. Tang, C. Girit, Z. Hao, M. C. Martin, A. Zettl, M. F. Crommie, Y. R. Shen, F. Wang, Nature 2009, 459, 820.

[20] S. Bhaviripudi, X. Jia, M. S. Dresselhaus, J. Kong, Nano Lett. 2010, 10, 4128.

[21] W. Liu, S. Kraemer, D. Sarkar, H. Li, P. M. Ajayan, K. Banerjee, Chem. Mater. 2014, 26, 907.

[22] S. Chen, W. Cai, R. D. Piner, J. W. Suk, Y. Wu, Y. Ren, J. Kang, R. S. Ruoff, Nano Lett. 2011, 11, 3519.

[23] M. J. Madito, A. Bello, J. K. Dangbegnon, C. J. Oliphant, W. A. Jordaan, T. M. Masikhwa, D. Y. Momodu, N. Manyala, J. Raman Spectrosc. 2016, 47, 553.

[24] M. J. Madito, N. Manyala, A. Bello, J. K. Dangbegnon, T. M. Masikhwa, D. Y. Momodu, RSC Adv. 2016, 6, 28370.

[25] A. C. Ferrari, D. M. Basko, Nat. Nanotechnol. 2013, 8, 235.

[26] Y. Hao, Y. Wang, L. Wang, Z. Ni, Z. Wang, R. Wang, C. K. Koo, Z. Shen, J. T. L. Thong, Small 2010, 6, 195.

[27] L. M. Malard, M. A. Pimenta, G. Dresselhaus, M. S. Dresselhaus, Phys. Rep. 2009, $473,51$. 
[28] A. C. Ferrari, J. C. Meyer, V. Scardaci, C. Casiraghi, M. Lazzeri, F. Mauri, S. Piscanec, D. Jiang, K. S. Novoselov, S. Roth, A. K. Geim, Phys. Rev. Lett. 2006, 97, 187401.

[29] J. M. Caridad, F. Rossella, V. Bellani, M. S. Grandi, E. Diez, J. Raman Spectrosc. 2011, 42, 286.

[30] J. M. Caridad, F. Rossella, V. Bellani, M. Maicas, M. Patrini, E. Díez, J. Appl. Phys. 2010, $108,84321$.

[31] M. Fabiane, S. Khamlich, A. Bello, J. Dangbegnon, D. Momodu, A. T. Charlie Johnson, N. Manyala, AIP Adv. 2013, 3, 112126.

[32] L. Liu, H. Zhou, R. Cheng, W. J. Yu, Y. Liu, Y. Chen, J. Shaw, X. Zhong, Y. Huang, $\mathrm{X}$. Duan, ACS Nano 2012, 6, 8241.

[33] H. Aoki, M. S. Dresselhaus, Eds., Physics of Graphene, Springer, New York, 2014.

[34] A. C. Ferrari, Solid State Commun. 2007, 143, 47.

[35] S. Lee, K. Lee, Z. Zhong, Nano Lett. 2010, 10, 4702.

[36] A. Dato, V. Radmilovic, Z. Lee, J. Phillips, M. Frenklach, Nano Lett. 2008, 8, 2012.

[37] W. Zhang, P. Wu, Z. Li, J. Yang, J. Phys. Chem. C 2011, 115, 17782.

[38] Q. Li, H. Chou, J. Zhong, J. Liu, A. Dolocan, J. Zhang, Y. Zhou, R. S. Ruo, S. Chen, W. Cai, Nano Lett. 2013, 13, 486.

[39] P. Zhao, A. Kumamoto, S. Kim, X. Chen, B. Hou, S. Chiashi, E. Einarsson, Y. Ikuhara, S. Maruyama, J. Phys. Chem. C 2013, 117, 10755.

[40] X. Li, C. W. Magnuson, A. Venugopal, R. M. Tromp, J. B. Hannon, E. M. Vogel, L. Colombo, R. S. Ruo, J. Am. Chem. Scociety 2011, 133, 2816.

[41] Y. Zhang, L. Zhang, P. Kim, M. Ge, Z. Li, C. Zhou, Nano Lett. 2012, 12, 2810.

[42] V. N. E. Robinson, J. L. Robins, Thing Solid Film 1974, 20, 155.

[43] A. Y. Tontegode, Prog. Surf. Sci. 1991, 38, 201.

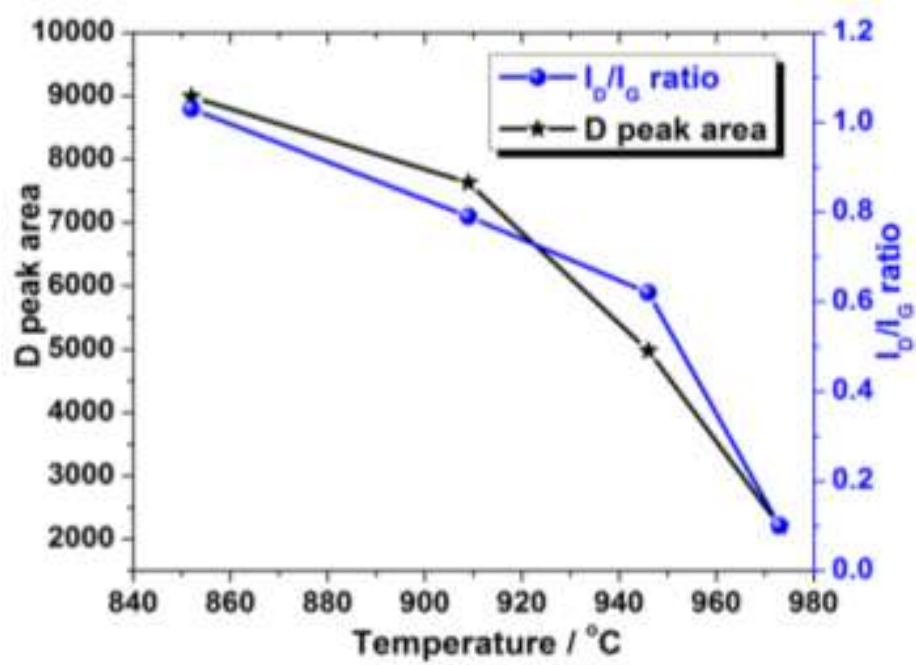

Table of contents (TOC): The AP-CVD graphene is uniform at low growth temperatures $\left(\sim 780-862{ }^{\circ} \mathrm{C}\right)$ with high disorders and becomes non-uniform at high growth temperatures $(\sim 956-973)$ with a very low disorder. 


\title{
Supporting Information
}

\section{Raman spectroscopy and imaging of Bernal-stacked bilayer graphene synthesized on copper foil by chemical vapor deposition: Growth dependence on temperature}

\author{
M. Fabiane ${ }^{1,2}$, M.J. Madito $^{1}$, A. Bello $^{1}$, and N. Manyala ${ }^{1 *}$ \\ ${ }^{I}$ Department of Physics, Institute of Applied Materials, SARChI Chair in Carbon Technology \\ and Materials, University of Pretoria, Pretoria 0028, South Africa
}

${ }^{2}$ National University of Lesotho, Department of Physics and Electronics, P.O. Roma, Lesotho

\section{Exfoliated graphene flake}

Figure $\mathrm{S} 1$ shows the Raman spectra (which show the D, G and 2D modes) and imaging data for micro-mechanical exfoliated graphene flake. Figure S1(a) shows an optical micrograph of a graphene flake on $300 \mathrm{~nm} \mathrm{SiO}_{2}$ with areas indicated as $1 \mathrm{~L}$ (monolayer graphene) and $2 \mathrm{~L}$ (bilayer graphene), while Fig. S1(b) shows corresponding typical Raman spectra of monolayer and bilayer graphene respectively of the flake. Raman imaging of $G$ peaks intensities of Raman spectra acquired from these areas displays the image color contrast between monolayer and bilayer graphene (Fig. S1(c)). The G peaks intensities for bilayer graphene is almost twice that of the monolayer graphene giving an insight into the number of layers present in the graphene sample because the $G$ peak intensity follows a linear trend as the number of layers increases from mono to multilayer graphene. ${ }^{[1-3]}$ Nonetheless, the 2D mode which is sensitive to the stacking order and the number of layers in a few layers graphene sample is adopted to determine the number of layers and the stacking order present in the sample. ${ }^{[2]}$ Figure S1(d) and (e) show the 2D mode of a Raman spectra for monolayer and bilayer graphene respectively (shown in Fig. S1(b)) and the Lorentzian fits. The 2D mode of a monolayer graphene shows a single Lorentzian with a full width at half maximum (FWHM) of $31 \mathrm{~cm}^{-1}$ and the bilayer graphene shows four Lorentzians each with FWHM of $31 \mathrm{~cm}^{-1}$ and wavenumbers at approximately 2655, 2680, 2700, and $2725 \mathrm{~cm}^{-1}$. The amplitudes of the two inner Lorentzians have a comparable intensity which is higher than that of the other two outer Lorentzians. The four Lorentzians in bilayer graphene arise from the electronic band splitting into two conduction and two valence bands resulting into splitting of the phonon bands. This (the four Lorentzians fitting) demonstrates characteristics of the AB stacking in bilayer graphene. ${ }^{[2]}$ Micro-mechanically exfoliated bilayer graphene flake from the Kish bulk graphite shows high-quality graphene with $\mathrm{AB}$ stacking without disorder peak that normally appears at around $1350 \mathrm{~cm}^{-1}$.

\footnotetext{
${ }^{*}$ Corresponding Author: Tel: +27 (0)12 4203549 and E-mail address: ncholu.manyala@up.ac.za (N. Manyala)
} 

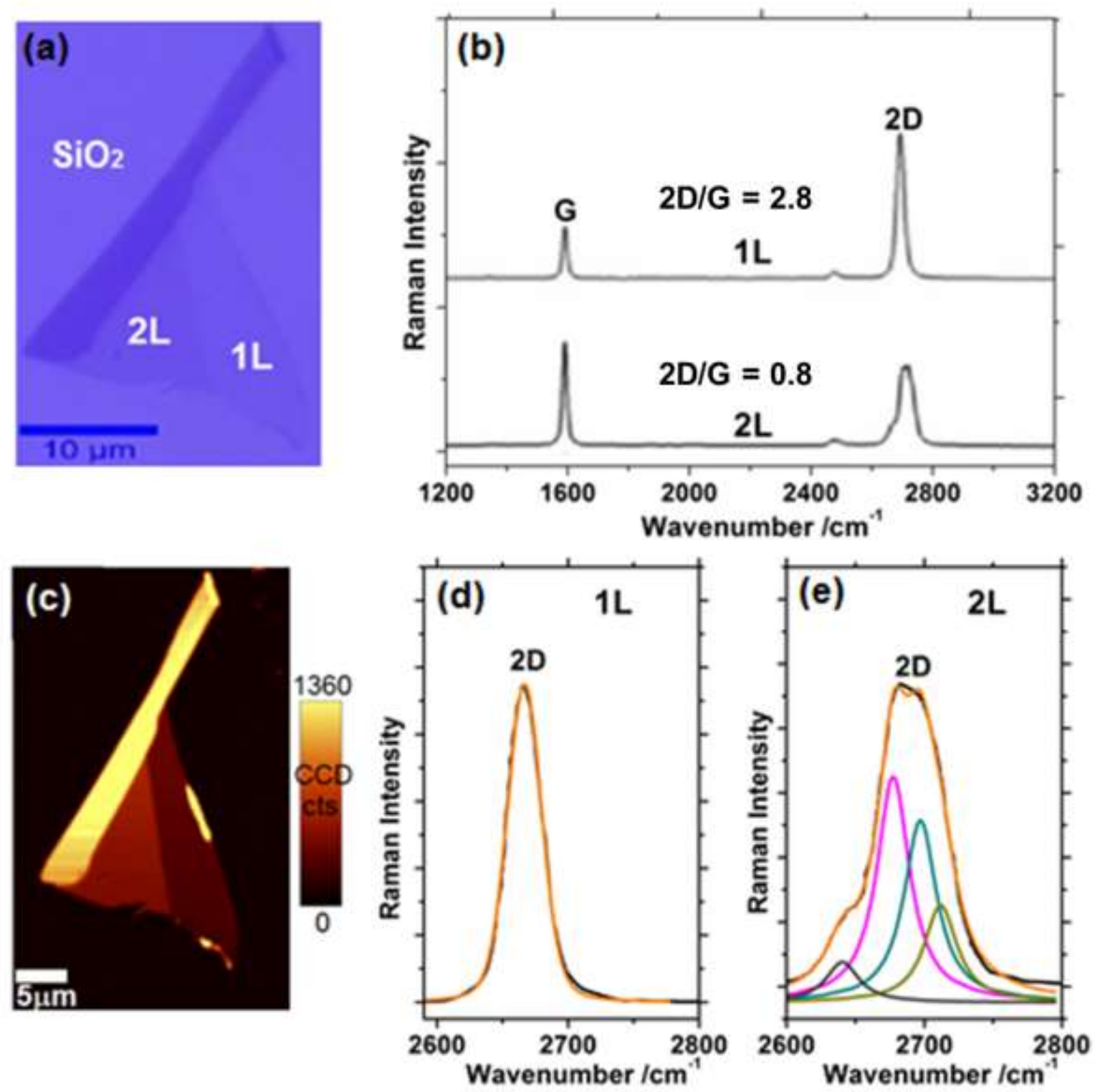

Figure S1. (a) An optical micrograph of graphene flake obtained by mechanical exfoliation of Kish graphite and (b) the corresponding Raman spectra obtained from areas indicated as 1L (monolayer graphene) and 2L (bilayer graphene) in (a). (c) Raman imaging of G peaks intensities of Raman spectra acquired from a graphene flake in (a). (d) The 2D mode of a monolayer layer and (e) the bilayer graphene showing Lorentzian fits. 


\section{AP-CVD graphene}

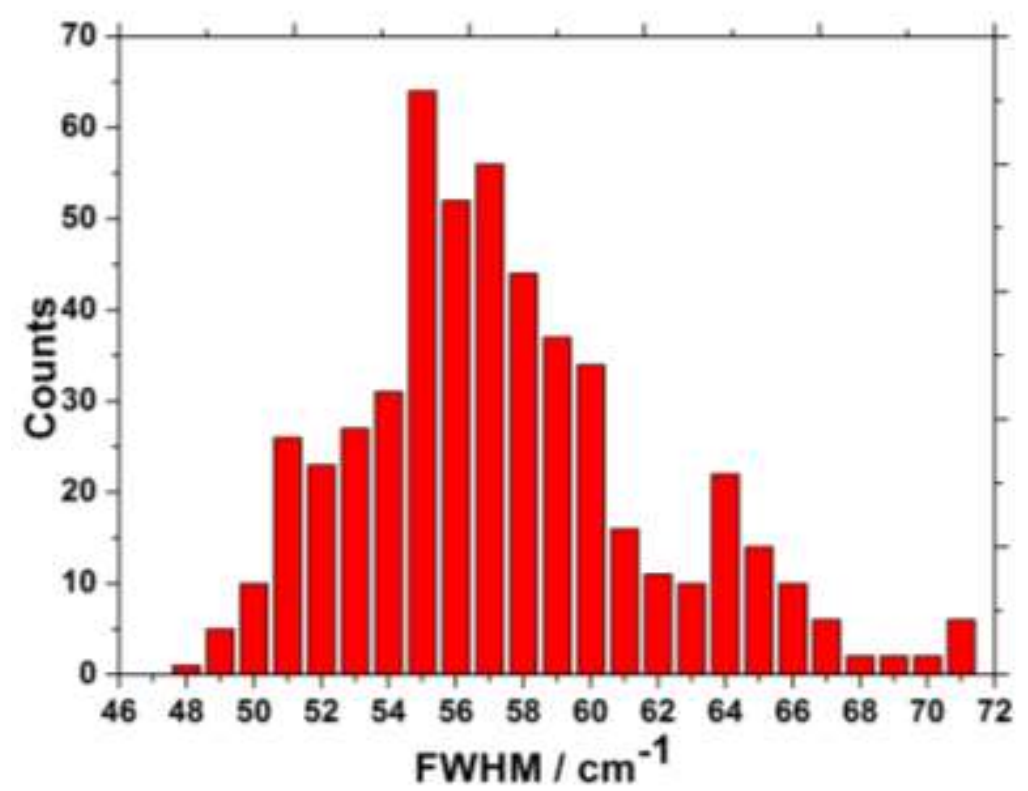

Figure S2. The distribution of the 2D peaks FWHMs for low-quality graphene of a $16 \mathrm{~cm}$ piece at $\sim 780-862{ }^{\circ} \mathrm{C}$.

\section{References}

[1] W. Fang, A. L. Hsu, R. Caudillo, Y. Song, A. G. Birdwell, E. Zakar, M. Kalbac, M. Dubey, T. Palacios, M. S. Dresselhaus, P. T. Araujo, J. Kong, Nano Lett. 2013, 13, 1541.

[2] A. C. Ferrari, J. C. Meyer, V. Scardaci, C. Casiraghi, M. Lazzeri, F. Mauri, S. Piscanec, D. Jiang, K. S. Novoselov, S. Roth, A. K. Geim, Phys. Rev. Lett. 2006, 97, 187401.

[3] L. M. Malard, M. A. Pimenta, G. Dresselhaus, M. S. Dresselhaus, Phys. Rep. 2009, 473,51 . 